\title{
Simulated Analysis of a Wheeled Tractor on Soft Soil Based on RecurDyn
}

\author{
Wenqian Huang ${ }^{1,2, * *}$, Feijun $\mathrm{Xu}^{1,2}$, Jishuai $\mathrm{Ge}^{1,2}$, and Chi Zhang ${ }^{1,2}$ \\ ${ }^{1}$ Beijing Research Center of Intelligent Equipment for Agriculture, \\ Beijing Academy of Agriculture and Forestry Sciences, Beijing, 100097, China \\ ${ }^{2}$ National Research Center of Intelligent Equipment for Agriculture, Beijing, 100097, China \\ huangwq@nercita.org.cn
}

\begin{abstract}
A simulation model of a wheeled tractor was built using the multibody dynamics software RecurDyn. The model consisted of four wheels, front and rear axles, and a body frame. An interaction model between tires and soft soil was established using the Soil-tire module of RecurDyn. The simulations of displacement and force of the tires were conducted on $20^{\circ}$ up-slope, $44^{\circ}$ ultimate up-slope, $20^{\circ}$ down-slope and $34^{\circ}$ ultimate down-slope roads respectively. The performance of a wheeled tractor over a cylindrical obstacle was analyzed under two different speeds. Results showed that forces of the front wheel were different on different slope roads. The maximum impact force of the front wheel increased by $68 \%$ as the up-slope increasing from $20^{\circ}$ to $44^{\circ}$. The maximum impact force of the front wheel decreased by $8 \%$ when the down-slope changing from $20^{\circ}$ to $34^{\circ}$. The maximum force of the front wheel decreased by $16 \%$ when the wheeled tractor over a cylindrical obstacle with the speeds decreasing from $1.356 \mathrm{~m} / \mathrm{s}$ to $0.678 \mathrm{~m} / \mathrm{s}$.
\end{abstract}

Keywords: wheeled tractor, soft soil, RecurDyn, simulation.

\section{Introduction}

A modern wheeled tractor has the advantages such as reliability, mobility and applicability, especially its wheels has no destructive effect on the road surface and soil, which make it the main agricultural machinery widely applied in agriculture [1]. As the complexity of a tractor and its operation environment, the design of a tractor using the traditional method is a long period and high cost process. With the development of the theory of vehicle and terrain systems and multi-body dynamics, it is feasible for us to design a tractor or analyze its performance using the techniques of modeling and simulation.

The vibration of wheeled tractors traveled on the rough ground was studied while the mechanics mode and equation of vibration was set up [2]. Influences of the change of the amplitude and space frequency of road surface roughness on adhesion

\footnotetext{
* Beijing Municipal Science and technology Commission (Project No. D101105046310003).

** Corresponding author.
} 
ability were simulated and analyzed by means of the nonlinear and time-varying tire mode [3]. The results showed that the adhesion ability of road to the tire reduced and the braking distance increased as the road surface roughness increased. The models of formative process of the effective spectrum of the soft terrain were developed and calculated [4]. A simplified, closed-form version of the basic mechanics of a driven rigid wheel on low-cohesion deformable terrain is studied [5].

In recent years, the development trend of a wheeled tractor is to design a compact structure, light, easy to operate and adaptable to different implements tractor. It is important to study the stability when a wheeled tractor was running on a slope land and over an obstacle. In this article, the interaction model of a tire and the soft land was developed using the Soil-tire module of the multi-body dynamics softwareRecurDyn. The trafficability and terrainability of a wheeled tractor on a slope land and over an obstacle were studied.

\section{$2 \quad$ Materials and Methods}

\subsection{Mechanical Relationship between Vehicles and Terrain}

In order to measure the deformation of soil under different loads, penetration tests are necessary. In these tests, the interaction between of the tire and soil is simulated using a plate penetrating into the soil, and the pressure-sinkage relationship can be calculated. For the homogeneous soil, a pressure-sinkage relationship equation was proposed by M.G. Bekker as follow [6-7]:

$$
p=\left(k_{\phi} / b+k_{c}\right) Z^{n}
$$

Where:

$b=$ plate width, $m$

$p=$ vertical average contact pressure, $\mathrm{kPa}$

$k_{\phi}=$ soil stiffness constant for sinkage, $\mathrm{kPal} \mathrm{m}^{n}$

$k_{c}=$ soil stiffness constant for sinkage, $\mathrm{kPal} \mathrm{m}^{\mathrm{p}-1}$

$Z=$ depth of sinkage, $m$

$n=$ soil constant related to the soil characteristics, non-dimensional

Equation (1) is suitable for the continuous loading process. For the unloading and loading cycle process, the calculation equation is showed as follow:

$$
p=p_{u}-\left(k_{0}+A_{u} Z_{u}\right)\left(Z_{u}-Z\right)
$$

Where:

$p_{u}=$ vertical average contact pressure at the start of unloading, $k P a$

$Z_{u}=$ depth of sinkage at the start of unloading, $m$

$k_{0}$ and $A_{u}=$ the characteristic parameters of the soil 


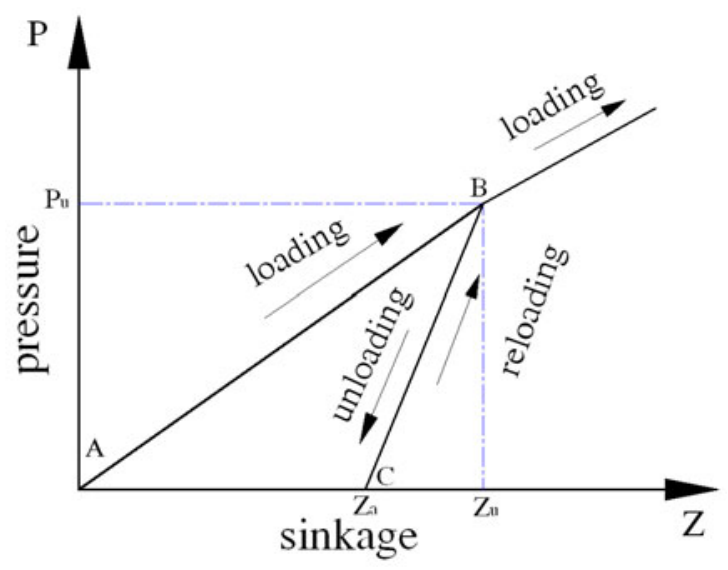

Fig. 1. The pressure-sinkage curve of the soil

The pressure-sinkage curve of the soil under the loading, unloading and reloading cycle process is shown in Fig.1. The line segment AB shows the continuous loading process. When reaching the maximum sinkage depth of $Z_{u}$, the unload process begins. The line segment BC shows the unloading process. When the pressure of soil reaches zero, a residual sinkage depth of $Z_{a}$ still exists as the elastic deformation of soil. The line segment $\mathrm{BC}$ also shows the reloading process. When reaching the sinkage depth of $Z_{u}$, the new sinkage depth would be showed through the elongation line along the line segment AB.

\subsection{Tire Mechanical Model}

All ground forces are acting on the tractor through the tire when the tractor is moving. Mechanical properties of the tractor tire have a very significant impact on manipulation and stability of a tractor [8-12]. There are several tire models which are used in a dynamics simulation [13-14]. The Soil-tire toolkit enables the vehicle motion to be simulated on the flat and uneven soft ground. The soft ground is more complex than the solid ground, so the definition of the contact area is crucial for the effect of the simulation. The contact area is obtained from the equilibrium of forces while taking into account the tire deflection and the sinkage, considering the resistance of soil deformation and the wheel load. Therefore, the Soil-tire model was adopted in this study.

The wheel load of Rigid wheel with soil dynamics model in the Soil-tier model was adopted. The pressure-sinkage relationship which is the basis of the theory of BEKKER is measured quasi-statically with low velocities. However, when driving off-load, the soil stress is not quasi-static, but dynamic. In order to take account of these dynamic effects in the calculation, dynamics parameters characterizing the soil strength have to be used as the following equation. The dynamic pressure sinkage relationship formula is

$$
p=\left(k_{\text {stat }}+k_{d y n} \cdot \dot{Z}^{m}\right) \cdot z^{n}
$$


Where: $k_{\text {stat }}$ is the pressure-sinkage parameter. $k_{d y n}$ is the pressure-sinkage parameter.

In the formula for the rigid wheel approach of BEKKER.

$$
F_{z}=\frac{b * D}{2} \cdot \int_{\theta_{\text {in }}}^{\theta_{\text {out }}} \sin (\theta) \cdot p(\theta) d \theta
$$

Where $b$ is the tier width, $m . F_{\mathrm{z}}$ is the wheel load, $N . D$ is the tier diameter, $m$. $\theta$ is the contact angle between tire and soil.

$\not \partial \theta)$ is replaced by the dynamic equation, so that the connection between the wheel load $F_{z}$ and sinkage $Z_{0}$ is calculated as follows.

$$
F_{z}=b \cdot \frac{D}{2} \int_{\theta_{\text {in }}}^{\theta_{\text {out }}}\left(k_{\text {stat }}+k_{\text {dyn }} \cdot \dot{z}^{m}\right) \cdot\left[\frac{D}{2} \cdot\left(\sin (\theta)-\sin \left(\theta_{\text {in }}\right)\right)\right]^{n} \cdot \sin (\theta) d \theta
$$

with

$$
\theta_{\text {in }}=\arcsin \left(\frac{\frac{D}{2}-z_{0}}{\frac{D}{2}}\right) ; \theta_{\text {out }}=\frac{\pi}{2}
$$

\subsection{Establishment of the Dynamic Model of a Wheeled Tractor}

As the four tires of a wheeled tractor are running on the same soil condition, the hypothesis that the four tires have the same road spectrum was proposed in this study. A simplified model of a wheeled tractor was set up using the multi-body dynamics analysis software RecurDyn. The simplified model includes four tires, a front axle, a rear axles and a vehicle frame. A reasonable mass was imposed on the front and rear axles. The four tires were created using the Soil-tier model of RecurDyn.

The parameters of a wheeled tractor model were listed in Table 1 . The fixed constraints were added between the vehicle frame and the front and rear axles. The revolution constraints were added between the tires and the front and rear axles. The model was driven using the motion imposed on the wheels. A step function was adopted in the creation of the motion shown as following.

$$
\left\{\begin{array}{l}
\text { when } x \leq x_{0}, \text { step }=h_{0} \\
\text { when } x_{0} \leq x \leq x_{1} \\
\text { step }=h_{0}+\left(h_{1}-h_{0}\right) \cdot\left(\frac{x-x_{0}}{x_{1}-x_{0}}\right)^{2} \cdot\left(3-2\left(\frac{x-x_{0}}{x_{1}-x_{0}}\right)\right) \\
\text { when } x \geq x_{1} \text {, step }=h_{1}
\end{array}\right.
$$

The motion function imposed on the four tires was: $5 \times$ step(time,0,0,0 $.1,1)$. The formula means that the revolution speed of the tires will increase from 0 to $5 \mathrm{rad} / \mathrm{s}$ in 0.1 second. The contact parameters between the tires and the soil can be set in RecurDyn, which was shown as Fig.2. 
Table 1. Simulated parameters of the tire model

\begin{tabular}{cccc}
\hline Parameter name & Parameter values & Parameter name & Parameter values \\
\hline $\begin{array}{c}\text { Wheelbase }(\mathrm{mm}) \\
\begin{array}{c}\text { Rear Wheel } \\
\text { track }(\mathrm{mm})\end{array}\end{array}$ & 1400 & $\begin{array}{c}\text { Front Wheel } \\
\text { track }(\mathrm{mm})\end{array}$ & 900 \\
\hline
\end{tabular}

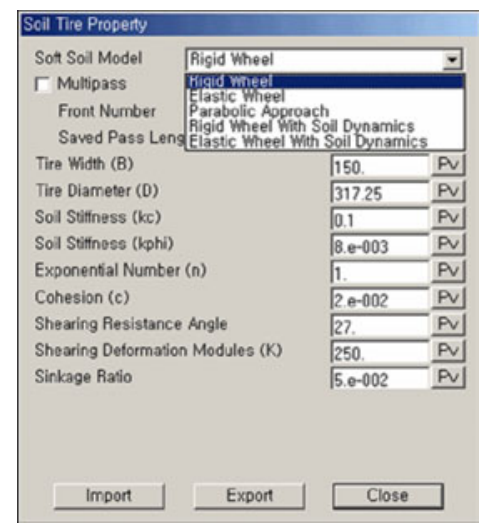

Fig. 2. Parameters of a tire model

\subsection{Kinematic and Dynamic Simulations of the Wheeled Tractor}

The wheeled tractor is a complex nonlinear multi-body system. The interaction process between the tire and the soil surface is a typical contact process [15-16]. RecurDyn is suitable to solve the multi-body dynamic problems with large-scale and complex contacts. The simulations of a wheeled tractor under three typical operation conditions were conducted respectively. The simulations of displacement and force of the tires were conducted on $20^{\circ}$ up-slope, $44^{\circ}$ ultimate up-slope, $20^{\circ}$ down-slope and $34^{\circ}$ ultimate down-slope roads respectively. The performance of a wheeled tractor over a cylindrical obstacle was analyzed under two different speeds. The road conditions of the simulation are the same as these in our another article [17].

\section{Results and Discussion}

\subsection{The Simulation of a Wheeled Tractor on an Up-Slope Road}

When the wheeled tractor is running on an up-slope rode, the front wheel contacts the road first. So the front wheel was chosen as the research object. As shown in Fig.3, $20^{\circ}$ and $44^{\circ}$ up-slope roads were created and a 500 sample times and 4 seconds simulation was conducted using RecurDyn. 


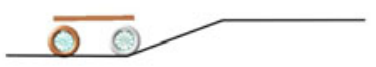

(a)

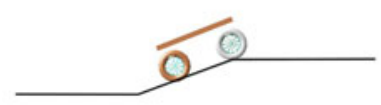

(c)

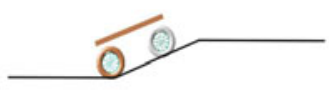

(b)

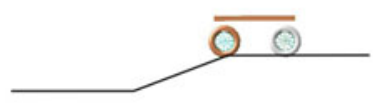

(d)

Fig. 3. The simulation process of a wheeled tractor on an up-slope road

As shown in Fig.4, the risk of a backwards rollover increased as the degree of the slope increased when the tractor was on an up-slope road, especially when the tractor was used to tow an implement or other heavy load. $44^{\circ}$ up-slope road is an ultimate situation that a backwards rollover occurs. A counterweight for the wheeled tractor can afford optimum weight distribution and improve the stability of operation on a steep slope to decrease the risk of a backward rollover.

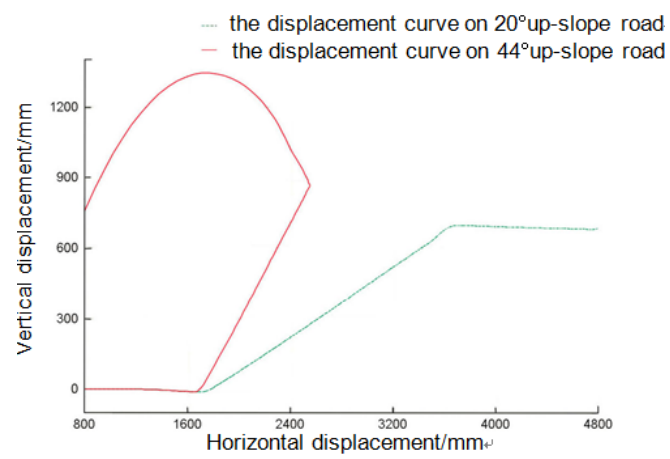

Fig. 4. The displacement curves of the front tire of a wheeled tractor on $20^{\circ}$ and $44^{\circ}$ up-slope roads

As shown in Fig.5(a), two peaks occurred in each normal force curve when the simulation time was 0.48 second and 1.4 second respectively, which were the transient normal impact forces generated in the contact-impact process between the front and rear tires and the steep slope road. The fluctuation reflected that there were a large amount of impacts when the complex non-linear tires were running over the road. As shown in Fig.5(b), when the simulation time was 1.7 second, the force on the front and rear tires was 0 when a backwards rollover happened. As shown in Fig.5(b), the force of the front tire when the wheeled tractor on a $44^{\circ}$ ultimate up-slope road increased by $68 \%$ compared with that on a $20^{\circ}$ up-slope road. 


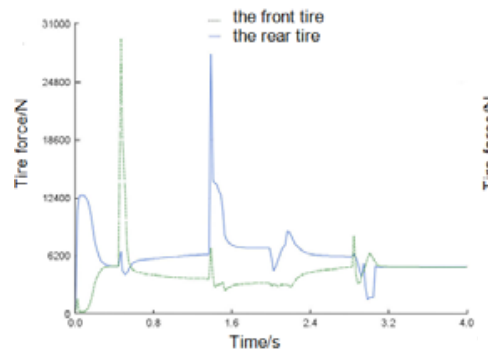

(a)

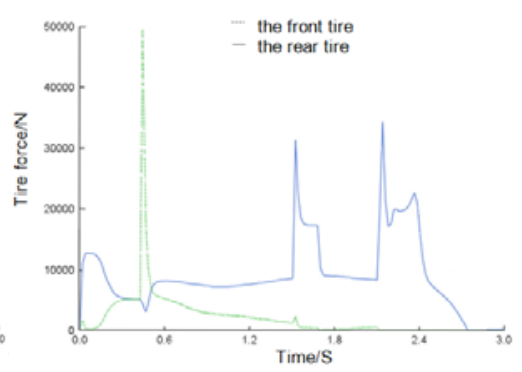

(b)

Fig. 5. The force curves of the front and rear tires on (a) $20^{\circ}$ and (b) $44^{\circ}$ up-slope roads

\subsection{The Simulation of a Wheeled Tractor on a Down-Slope Road}

In the simulation of a wheeled tractor running on a down-slope road, the rear tire was chosen as the research objective. As shown in Fig.6, $20^{\circ}$ and $34^{\circ}$ down-slope roads were created and a 500 sample times and 4 seconds simulation was conducted using RecurDyn.

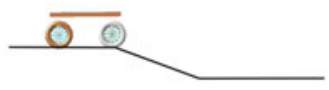

(a)

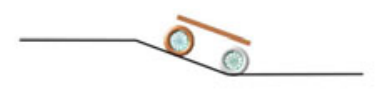

(c)

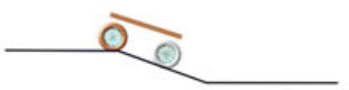

(b)

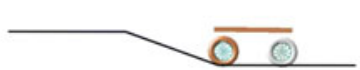

(d)

Fig. 6. The simulation process of a wheeled tractor on a down-slope road

As shown in Fig.7, the risk of a rollover still existed when the tractor was running on a down-slope road. $34^{\circ}$ down-slope road is an ultimate situation that a rollover occurs. Because of the high speed and a large inertia when the tractor was running on a down-slope road, the risk of a rollover increased as the emergency brake or the collision with an obstacle occurred. 


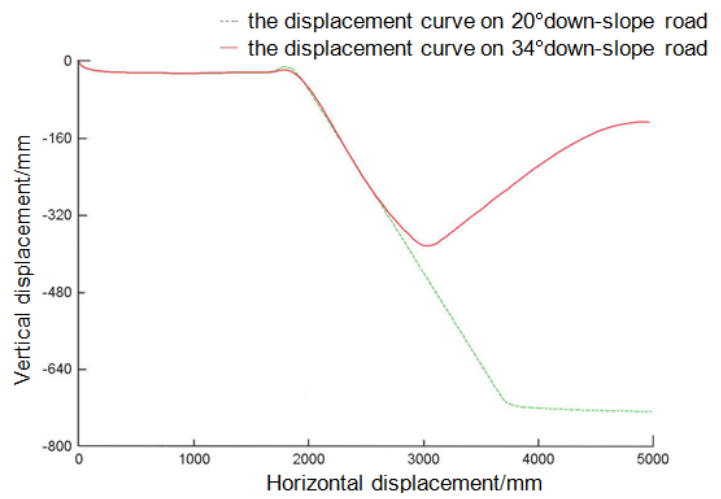

Fig. 7. The displacement curves of the rear tire of a wheeled tractor on $20^{\circ}$ and $34^{\circ}$ down-slope roads

The simulation result of a wheeled tractor on a $20^{\circ}$ down-slope road was shown as Fig.8(a). When the simulation time was 0.46 second, the front tire began to contact with the road, and the force on the tire increased as the contact area between the tire and the road increased when the tractor was moving forward. When the simulation time was 1.22 second, the rear tire began to contact with the road, and the force between the rear tire and the road decreased dramatically as the front tire was moving forward steadily. The simulation result of a wheeled tractor on a $34^{\circ}$ down-slope road was shown as Fig.8(b). As the force curves of the front tires shown in Fig.8(b), the maximum transient force of the front tire on the $34^{\circ}$ down-slope road decreased by $8 \%$ compared with that on the $20^{\circ}$ down-slope road. When the simulation time was 1.22 second, the force on the rear tires was 0 when a rollover happened.

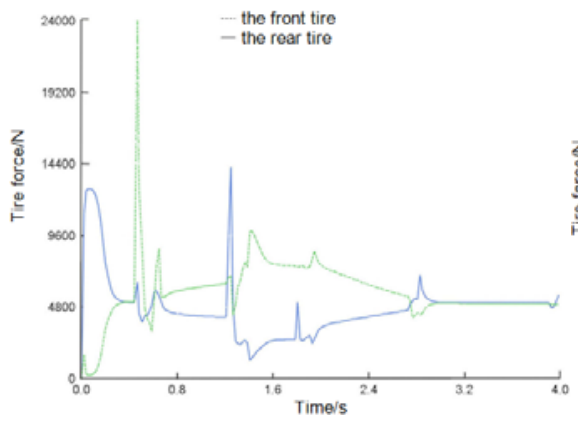

(a)

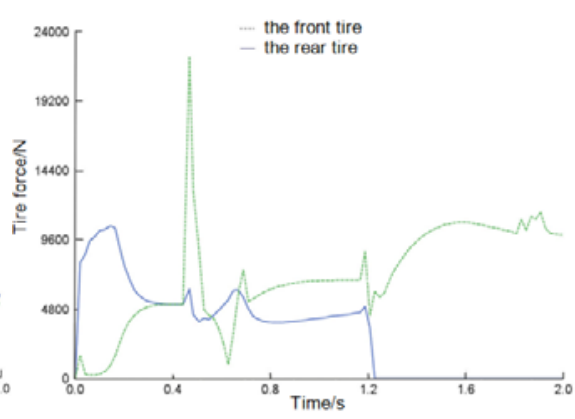

(b)

Fig. 8. The force curves of the front and rear tires on (a) $20^{\circ}$ and (b) $34^{\circ}$ down-slope roads

\subsection{The Simulation of a Wheeled Tractor over an Obstacle}

As shown in Fig.9, a cylindrical obstacle was created and a 500 sample times and 4 seconds simulation was conducted using RecurDyn. The diameter of the obstacle was $200 \mathrm{~mm}$ and a half of it was embedded into the soil. The speeds that the wheeled tractor running over the obstacle were $1.356 \mathrm{~m} / \mathrm{s}$ and $0.678 \mathrm{~m} / \mathrm{s}$ in the simulation. 


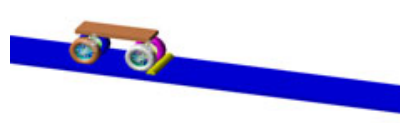

(a)

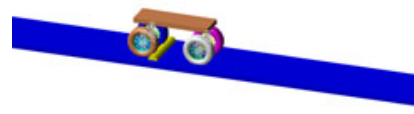

(c)

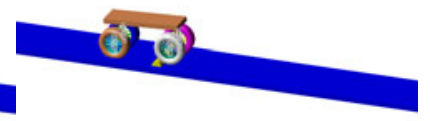

(b)

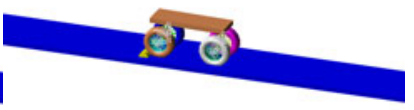

(d)

Fig. 9. The simulation process of a wheeled tractor over a cylindrical obstacle

The simulation result of the wheeled tractor over a cylindrical obstacle was shown as Fig.10. Two impact forces on the front and rear occurred respectively when the tractor was running over the cylindrical obstacle, and the force on the front tire was obviously larger than the one on the rear tire. The maximum force of the front tire when the wheeled tractor running over the obstacle at a speed of $0.678 \mathrm{~m} / \mathrm{s}$ decreases by $16 \%$ compared with that at $1.356 \mathrm{~m} / \mathrm{s}$. It is necessary to increase the distance between the right tire and the left tire and decrease the speed for a stable operation on an uneven road and avoidance of a rollover in a sudden collision with an obstacle.

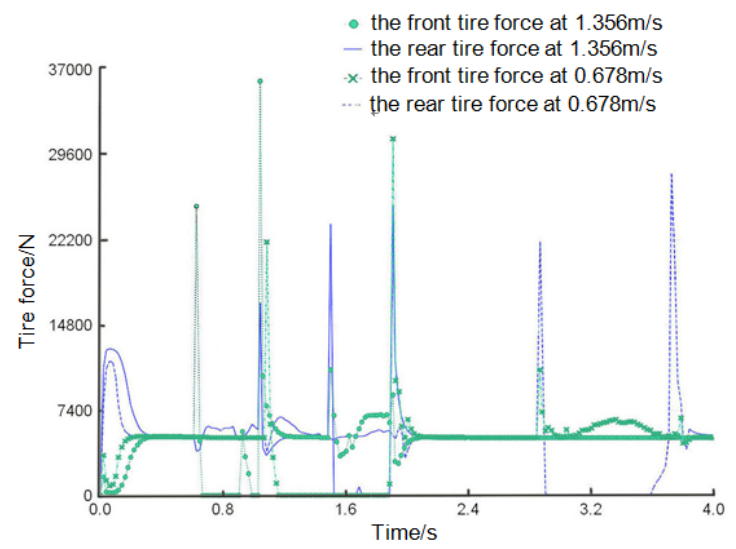

Fig. 10. The force curves of the front and rear tires over a cylindrical obstacle

\section{Conclusion}

The dynamic model of a wheeled tractor was established using Soil-tire module of RecurDyn. The simulations of displacement and force of the tires were conducted on 
$20^{\circ}$ up-slope, $44^{\circ}$ ultimate up-slope, $20^{\circ}$ down-slope and $34^{\circ}$ ultimate down-slope roads respectively. The tire force that the wheeled tractor runs over a cylindrical obstacle was analyzed at two different speeds. The conclusions are as following:

The forces of the front wheel were different on different slope roads. The maximum impact force of the front wheel increased by $68 \%$ as the up-slope increasing from $20^{\circ}$ to $44^{\circ}$. The maximum impact force of the front wheel decreased by $8 \%$ when the downslope changing from $20^{\circ}$ to $34^{\circ}$.

The maximum force of the front wheel decreased by $16 \%$ when the wheeled tractor over a cylindrical obstacle with the speeds decreasing from $1.356 \mathrm{~m} / \mathrm{s}$ to $0.678 \mathrm{~m} / \mathrm{s}$.

Acknowledgments. Our project is supported by Beijing Municipal Science and technology Commission (Project No. D101105046310003).

\section{References}

1. Wang, X.: Adaptability Comparison between Wheeled and Crawler Tractor. Tractor \& Farm Transporter (2), 1-2 (2006)

2. Wang, X., Yu, Q., Hu, W., Xu, Y.: The Establishment of Traveling Vibration Mechanics Model and Equation of Vibration of Wheeled Tractors. Journal of Heilongjiang August First Land Reclamation University (3), 45-48 (1998)

3. Zuo, S., Cheng, Y.: Simulation Analysis of the Influence of Road Surface Roughness on Tyre Dynamic Performance in Vehicle Braking. Transactions of the Chinese Society of Agricultural Engineering 16(4), 42-45 (2000)

4. Zheng, L., Liu, M., Zhang, Y., Wang, D.: Formative Process Analysis of the Effective Spectrum of the Soft Terrain Surface. Transactions of the Chinese Society of Agricultural Engineering 10(2), 29-34 (1994)

5. Shibly, H., Iagnemma, K., Dubowsky, S.: An Equivalent Soil Mechanics Formulation for Rigid Wheels in Deformable Terrain. with Application to Planetary Exploration Rovers. Journal of Terramechanics 42, 1-13 (2005)

6. Bekker, M.G.: Theory of land locomotion-the mechanics of vehicle mobility. University of Michigan Press (1956)

7. Wong, J.Y.: Theory of Ground Vehicles. John Wiley \& Sons, New York (1993)

8. Chen, Z., Yu, G.: Experimental Study on the Trafficability of Small-sized Desert Shrub Harvester and Its Effects on Sandy Land. Journal of Anhui Agricultural Science 36(31), 13521-13522, 13543 (2008)

9. Chen, W., Zhao, C., Liu, J.: Simulation Analysis on the Tractive Characteristics of Wheels in the Sands. Journal of Chongqing University (Natural Science Edition) 35(3), 15-18, 29 (2006)

10. Chen, W.: Analysis on Tractive Characteristics of a Wheel on Sands. Tractor \& Farm Transporter 29(6), 22-23, 25 (2008)

11. Peng, Y.: Wheeled Tractor Pulling Characterize and Applied Research. Journal of Agricultural Mechanization Research (1), 173-175 (2007)

12. Bi, X., Wang, Y.: Factors Effect and Improving Measures on Traction Efficiency of Wheeled Tractor. Tractor \& Farm Transporter 34(6), 11-12 (2007)

13. Hu, J., Li, T., Qin, D.: Modeling and Simulation of Electric Power Steering System Based on Vehicle Whole Dynamics. Journal of System Simulation 20(6), 1577-1581 (2008)

14. Leng, S., Gao, L., Wang, S., Zhu, Y.: Dynamics Model Analysis on Five-axle Vehicle with All-wheel Steering. Transactions of the Chinese Society of Agricultural Machinery 39(12), 39-44 (2008) 
15. Schmid, I.C., Harnisch, C., Lach, B.: Terrain-Vehicle Interactions in Virtual Reality. In: Seoul 2000 FISITA World Automotive Congress, Seoul (2000)

16. Choi, H.D., Kang, H., Hyun, K.H., Kim, S., Kwak, Y.K.: Force Distribution Estimation of Wheeled Mobile Robot: Application to Friction Coefficients Estimation. In: 17th IFAC World Congress (IFAC 2008), Seoul (2008)

17. Xu, F., Huang, W., Chen, L.: Simulation analysis of tire force of wheeled tractor under typical road conditions. Transactions of the Chinese Society of Agricultural Machinery 25(S2), 61-65 (2009) 